\title{
HEADWAY MODELING IN NORTHERN IRAQI TWO-LANE HIGHWAYS
}

\author{
Ayman A. AbdulMawjoud \\ College of Engineering, University of Mosul - Iraq
}

\begin{abstract}
Headway is the time interval between passages of successive vehicles past a point on the highway. More than 8000 car headways were observed in 10 level and rolling terrain two-lane highways in northern Iraq to find the critical headway and headway distribution and modeling for these highways. It is found that the critical headways are ranges between 2.5 to 4.0 seconds with a suitable critical headway of 3.2 second. The best headway model consists of composite model, for free vehicles it is a shifted negative exponential distribution, while for constrained vehicles it is
\end{abstract} a lognormal distribution.

KEYWORDS : Two-lane highway, Headway modeling, Critical headway, headway distribution, Traffic flow.

\section{INTRODUCTION}

Headways are the time interval between the passages of successive vehicles past a point on the highway (Highway Research Board, 2000). Because the inverse of the mean time headway is the rate of flow, headway has been described as the fundamental building blocks of traffic flow (Salter, 1990). When the traffic flow reaches its maximum value, then the time headway reaches its minimum value. Although headway is seemingly simple aspect of traffic flow, they can be used collectively as an index of the level of stream congestion (Dawson \& Chimini, 1968). Vehicles traveling on a twoway two-lane are either free or following (Kell, 1962; Dawson \& Chimini, 1968; Grecco \& Sword, 1968; and Schuhl, 1971). A free vehicle is unaffected by the preceding vehicle and it travels at its desired speed. A following vehicle is forced to travel at the speed of the preceding vehicle until an overtaking opportunity is presented at which time it may overtake and become a free vehicle. The balance between these free and following vehicles varies with the flow rate of the traffic stream. As the flow rate increases the proportion of free vehicle decreases and the proportion of following vehicles increase (Dawson \& Chimini, 1968).

Academic Journal of Nawroz University

(AJNU) Volume 7, No 4 (2018).

Regular research paper : Published 8 December 2018

Corresponding author's e-mail :

aymanmawjoud@uomosul.edu.iq

Copyright @2017 Ayman A. AbdulMawjoud

This is an open access article distributed under the Creative

Commons Attribution License.

\section{BACKGROUND}

\subsection{Critical Headways}

The early research into critical headway was undertaking by the U.S. bureau of public road in the 1930. There is interaction between successive vehicles up to nine-sec apart (Hoban, 1984). Previous studies have suggested and employed a critical headway criterion to define vehicle as following if the headway is less than the critical value. Critical headways employed in these studies ranged from 3 to 7 seconds (Keller, 1976). The literature also showed that the percentage of impeded drivers is very sensitive to the headway criteria employed. Hoban (1980) found that the percentage of following drivers increased from $45.6 \%$ to $60.1 \%$ as the critical headway criterion increased from 3 to 5 seconds. No quantitative data on the willingness of following drivers to overtake is available. Wolhuter (1989) termed the zone where traffic is either free or following as the "partially constrained" region. This region is very important and in many respects, it is an over-simplification to treat the critical headway as unique value. In reviewing of literatures one finds a wide range of values employed for the critical headway. Table (1) lists some of the values reported in different countries. 
Table (1) : Critical Headway Recommended by Various Authors

\begin{tabular}{|c|c|c|}
\hline Critical Headway in sec & Country & Source \\
\hline 4.0 & Australia & Hoban (1980, 1983) \\
\hline 4.0 & South Africa & Wolhuter (1989) and Van As (2004) \\
\hline 5.0 & Australia & Underwood (1963) \\
\hline 5.0 & U.S.A. & TRB 1985 \\
\hline 3.0 & U.S.A. & Krumins (1981) \\
\hline 6.0 & Canada & \\
\hline
\end{tabular}

In 2000 edition of the HCM, the value chosen for the critical headway may have a significant impact on the Percent Time Spent Following (PTSF), and thus the LOS. Guell and Virkler (1988) and Johnson (1995) expressed dissatisfaction with the 5-sec headway criterion recommended in $1985 \mathrm{HCM}$ for use in estimating percent time delay from spot platooning data in the field. Guell and Virkler (1988) suggested that a headway criterion in 4 secs would provide more useful LOS categories. Johnson (1995) stated that the 5sec value has been replaced with 2.5 to $3.5 \mathrm{sec}$ in work for California counties.

\subsection{Headway distributions and Modeling}

Traffic flow is an extremely complex phenomenon and its complete understanding is so difficult. However, headway can help to explain the nature of traffic flow to some extent. The distributions of headway in the traffic stream are so important for microscopic traffic flow characteristics (McLean, 1989, Chandra \& Kumar, 2001). It is not surprising therefore, that many attempts have been made to develop models of headway distribution. The general goal in developing a headway modeling has been to find a mathematical function which statistically "fits" observed headway distributions. The functional forms have been chosen based on theoretical consideration. For example, by using composite distributions to differentiate between free and following vehicles. It has been recognized for long time that, for low volumes the arrival at a point on the road is essentially random and thus follows a Poisson distribution (Gerlough \& Huber, 1975). A Poisson distribution leads to the negative exponential headway distribution given in the following equation:

$$
P(h<t)=1-\exp \left(-\frac{t}{T}\right)
$$

where,

P: probability of headway less than $t$ sec,

$\mathrm{h}$ : headway in sec,

$\mathrm{t}$ : time in sec, and

$\mathrm{T}$ : mean headway in sec.

The equation predicts that there is a finite probability for all $t \geq 0$. Since vehicles must maintain a certain minimum headway, at least equivalent to the length of the preceding vehicle, it is necessary to shift the distribution to account for this. This result in the shifted negative exponential distribution, which is given by equation (Gerlough \& Huber, 1975):

$$
\mathrm{P}(\mathrm{h}<\mathrm{t})=1-\exp \left(-\frac{\mathrm{t}-\tau}{\mathrm{T}-\tau}\right)
$$

where, $\tau$ is the minimum headway for following vehicles. The negative exponential distribution or its variation has been found to provide a good fit of data at low flow but it has usually proved to be inadequate as traffic interactions become pronounced (Dommerholt \& Botma, 1988; Botma, 1988; Salter, 1990). Wolhuter (1989) indicates that in South Africa it applies up to a volume of $500 \mathrm{veh} / \mathrm{hr}$. More complex models have been developed for modeling headways at higher volumes. Some researchers have employed alternative distributions such as the lognormal, gamma or Erlang distribution. However, these have not always been found to be applicable for all situations. This is because there are two different modes of travel free and following and no single distribution can adequately model both states. This has led to the development of composite models, which explicitly differentiate, between the free and following states.

Schuhl (1971) proposes a composite model of shifted and unshifted exponential distributions:

$$
P(h<t)=(1-\alpha)\left[1-\exp \left(-\frac{t}{T_{1}}\right)\right]+\alpha\left[1-\exp \left(-\frac{t-\tau}{T_{2}-\tau}\right)\right]
$$

where,

$\alpha$ :fraction of total flow made up of constrained vehicles,

T1: average headway of free-following vehicles, and

T2: average headway of constrained vehicles. 
To overcome the problems with the Schuhl model at high volumes, other authors have used different distributions for the following vehicle component of a composite model. For example, the hyperlang model is use an Erlang distribution for the following vehicles while the hyperlog model is use a lognormal distribution for these vehicles (Krumins, 1988). Both these latter models are used the negative exponential distribution for the free vehicles. Ovuworie et al. (1980) proposed a three-parameter model composed of a normal distribution and two displaced exponential distributions. In an Australian research study, Buckley (1962) proposed a compound headway model and used a normal distribution to describe the constrained headways. May (1965), Greenberg (1966), Daou (1966), and Tolle (1971), suggested the lognormal function as a headway model. The lognormal function, however, is merely a mathematics transformation that tends to approximate several members of the family of Erlang functions. Dawson \& Chimini (1968) and Chandra \& Kumar (2001) proposed a hyper-Eralng (hyper-lang) distribution which is selected to describe the headway distribution reported in the 1965 HCM (1965). Saha et al. (2017) shows that exponential or Erlang distributions exhibit appropriate headways up $\mathrm{V} / \mathrm{C}$ ratio of 0.3 , while gamma and exponential distributions were convenient for headway data corresponding to a $\mathrm{V} / \mathrm{C}$ ratio of 0.4 and above. Roy and Saha (2018) conduct a field study on two-lane highways in India, which show hesitation in its traffic composition, suitable models were selected using a methodology based on K-S test and followed by field validation. They concluded that under moderate flow, a Log-logistic distribution is a best headway model, whereas for congested state of flow a Pearson 5 is the best one.

\subsection{Objective of the Study}

The goals of this study are to:

A. Find the critical headway for rural two-lane highways under study.

B. Find the best headway distribution and modeling for these highways.

\section{DATA COLLECTION METHODOLOGY}

The type of sites that were selected included sites with high to moderate traffic volumes in both level and rolling terrain with sufficient sight distance. A total of 10 field sites in three governorates in northern Iraq i.e., Mosul, Erbil and Dohuk were selected. A Video camera was placed and played on the roadside, the measurements were carried out simultaneously at both lanes. Marking was fixed at pavement as reference point for measurement. Video camera was hidden from the view of the driver because it may influence their driving behavior. The recorded film was played on a monitor screen to extract the headway information and the times of passage were manually transferred into computer files. A total of about 8000 car headways were observed and classified during these investigations.

\section{ANALYSIS AND RESULTS}

The headway between successive vehicles was conducted. An important parameter established is the maximum headway at which vehicle follow. This maximum headway is used to establish percentage followers. A vehicle is classified as "following" when headway between the vehicle and the preceding vehicle is less than this maximum. An investigation was undertaken in which the lengths of headways were measured to accuracy of 0.1 second and vehicles were classified manually as following or non-following. A headway model was obtained by forming a combination of the free and constrained components. Plots of the percentage cumulative headway distributions of entry headway depicting the data sets obtained in this study are shown in Figure (1). Figure (1 a \& b) for highways in Mosul governorate, Figure (1c) for highways in Erbil governorate, while Figure (1d) for highways in Dohuk governorate. The general from of the regression model was established. Its formulation is given as:

percentagecumulativeofheadway $=a+$

$b \ln$ (headway)

It is shown from the figure and Table (2) that the percentage cumulative distribution starts for headway at entry of 1 second. After this, the curve increases until a maximum curvature is reached, these points are unclear, but between 3 and 6 seconds. Headways for any percentage cumulative distribution are different for the highways and depending on the traffic volume for that highway.

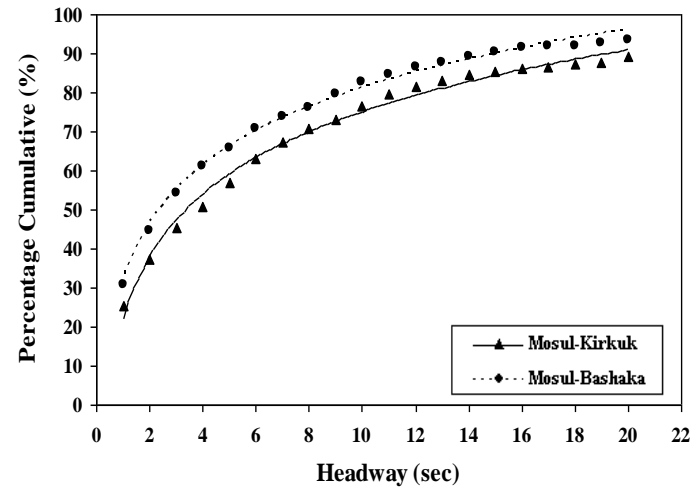

(a) Mosul Highways - Right Side 


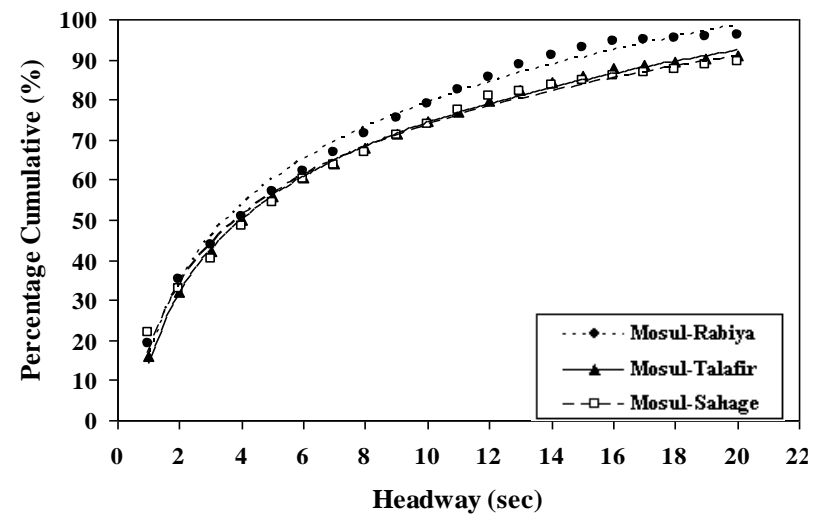

(b) Mosul Highways - Left Side

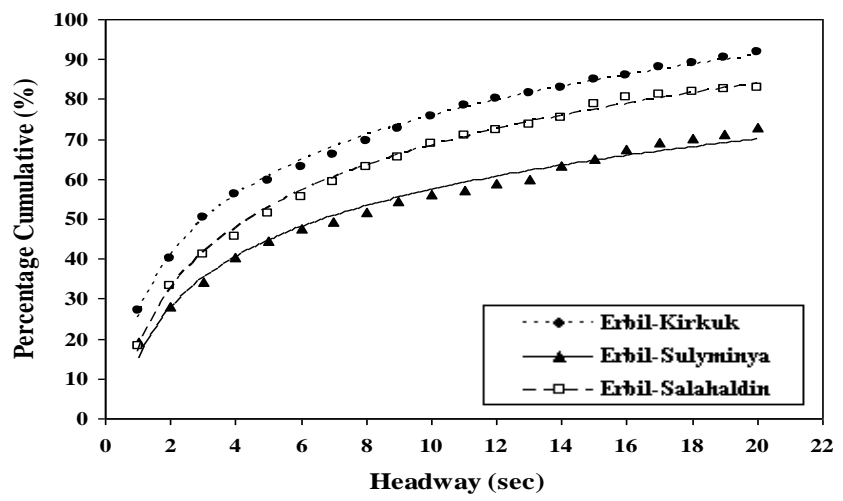

(c) Erbil Highwavs

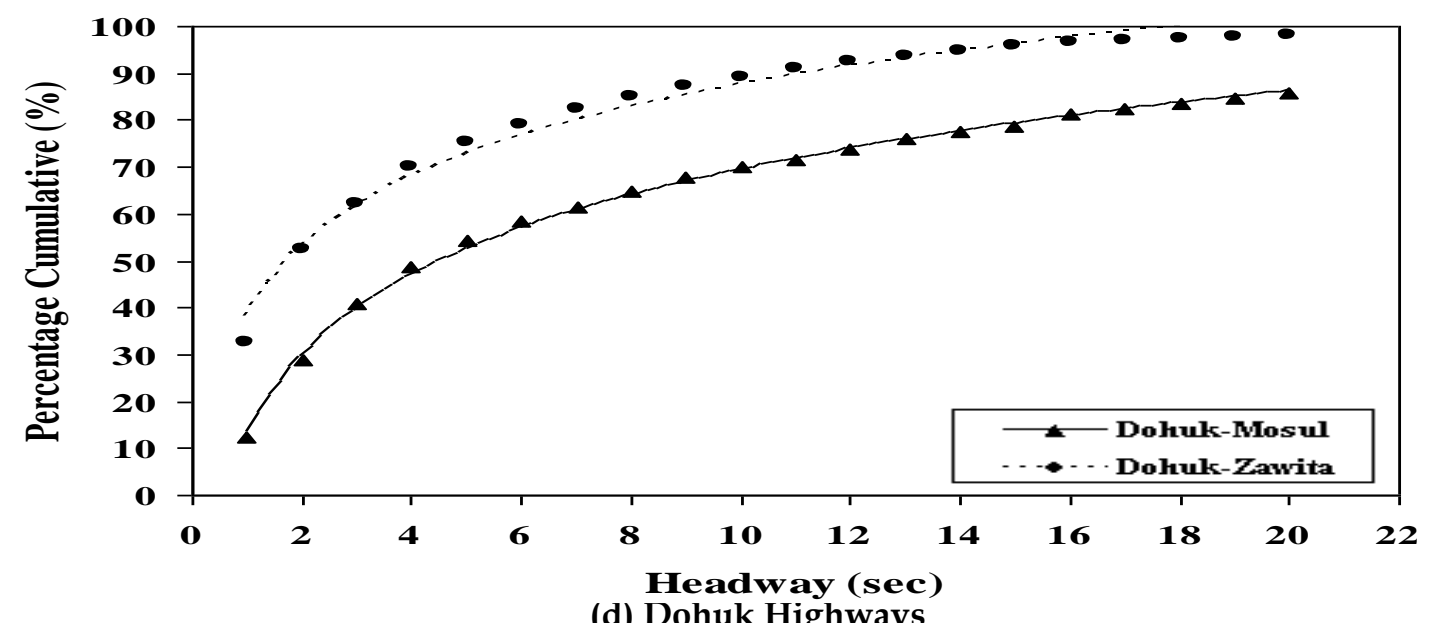

Fig ( 1 ) : Percentage cumulative headway distributions

Table (2) : Percentage Cumulative Headway Parameters

\begin{tabular}{|c|c|c|c|}
\hline Highway & A & B & R2 \\
\hline Mosul -Kirkuk & 22.401 & 22.905 & 0.99 \\
\hline Mosul -Bashaka & 31.124 & 21.684 & 0.996 \\
\hline Mosul -Rabiya & 14.971 & 27.855 & 0.99 \\
\hline Mosul -Talafir & 14.332 & 26.082 & 0.998 \\
\hline Mosul -Sahage & 16.642 & 24.737 & 0.99 \\
\hline Erbil -Kirkuk & 25.493 & 21.815 & 0.997 \\
\hline Erbil -Sulyminya & 15.500 & 18.223 & 0.99 \\
\hline
\end{tabular}




\begin{tabular}{|c|c|c|c|}
\hline Erbil -Salahaldin & 16.621 & 22.421 & 0.997 \\
\hline Dohuk -Mosul & 13.693 & 24.309 & 0.998 \\
\hline Dohuk -Zawita & 38.297 & 21.359 & 0.98 \\
\hline
\end{tabular}

Plots of the probability headway $\geq \mathrm{t}$ second for the same sites are shown in Figure (2). A mathematical model for this relation is,

Probabilityheadway $\geq t=a e^{b(h e a d w a y)}$

$a$ and $b$ are shown in Table (3). The several plots
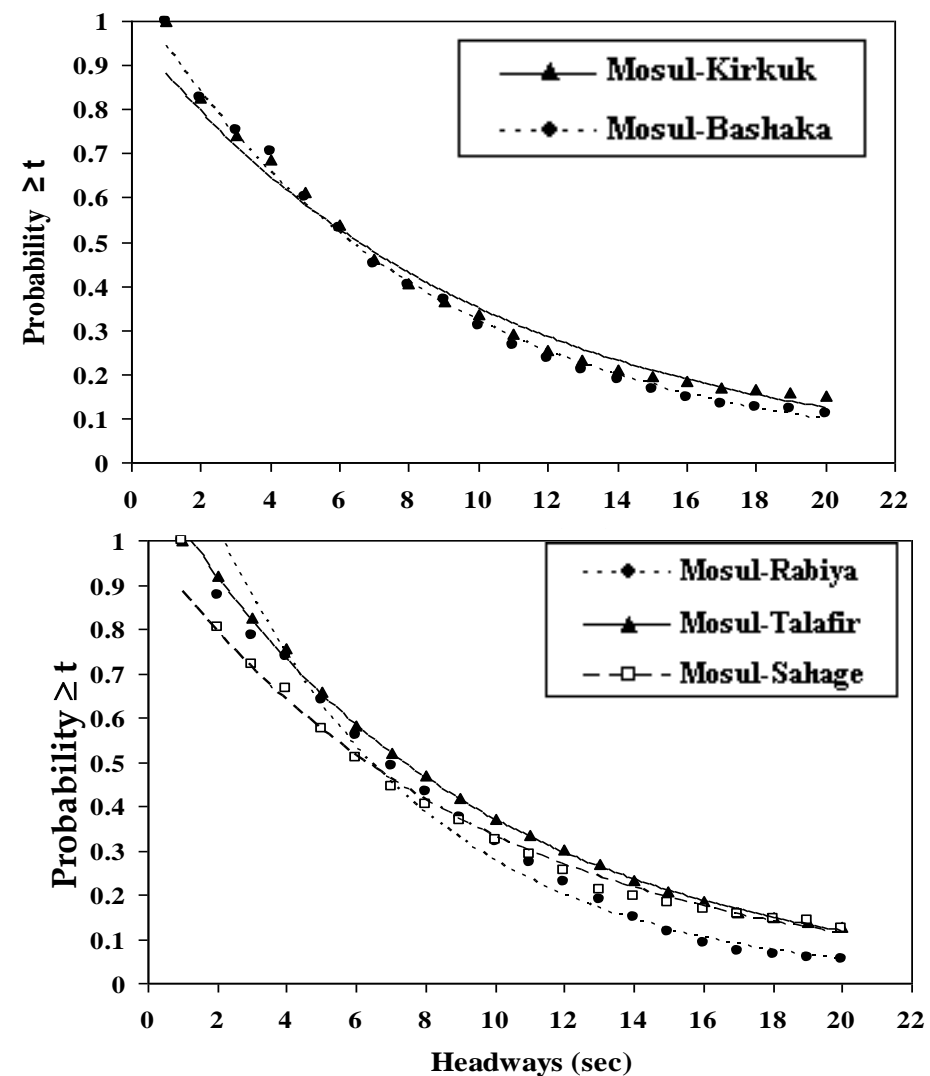

(b) Mosul Highways - Left Side

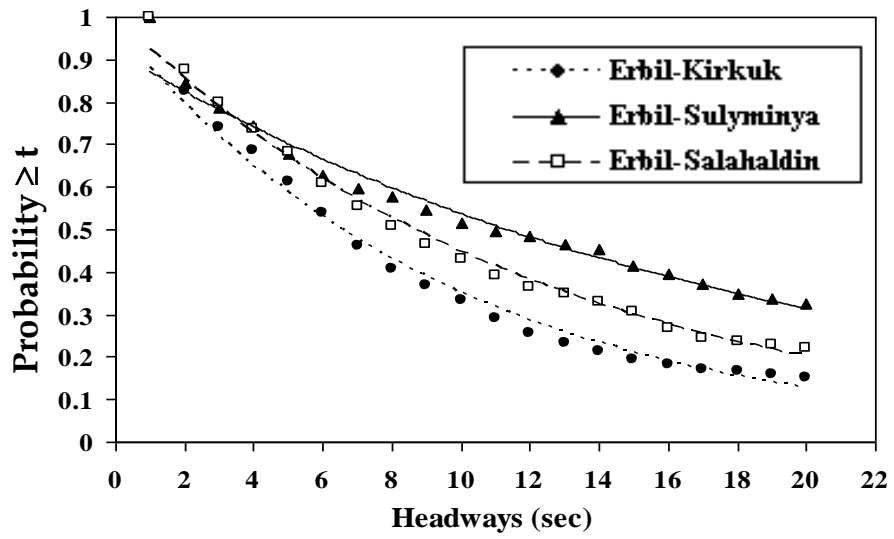

(c) Erbil Highways obtained from the highways were purported to represent flow rates ranging from 500 to $1800 \mathrm{vph}$, and in general, they tend to form a uniform family . However, it should be observed that the proportion of short headways increases with increasing traffic flow.

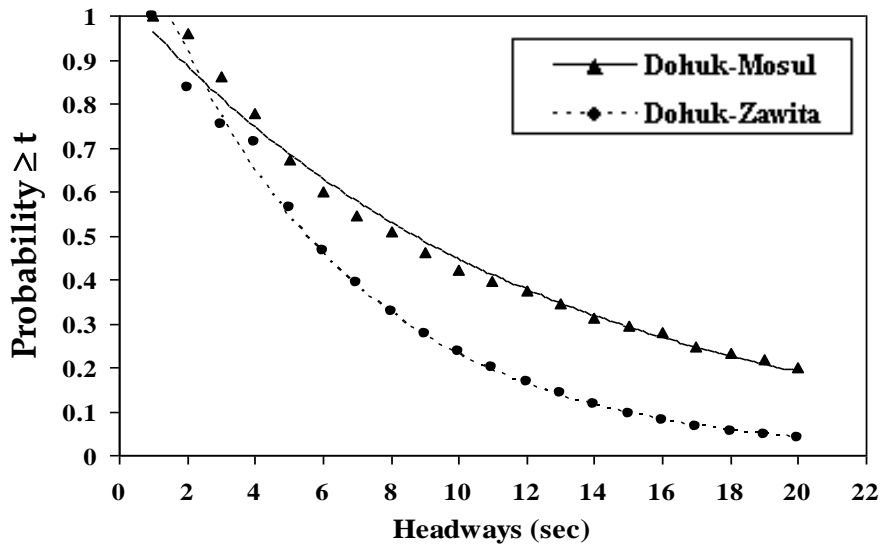

(d) Dohuk Highways

Fig (2) : Probability Headway $\geq t$ Second

\subsection{Critical Headway}

The results of the investigation of critical headway are shown in Figure (3) which shows the probability of a vehicle not following at different lengths of headways. The figure shows that this probability increases with longer headway. Below the headway values of 2.5 seconds it is likely that vehicles are following. While at headways greater than 4 seconds it is more likely that vehicles are not following. The results of the investigation indicate that headway of about 3.2 seconds would be suitable as the maximum (or following headway). This 3.2 second headway is little longer than the 3.0 seconds recommended by the $2000 \mathrm{HCM}$ (2000). However, the critical headway depends primarily on the traffic volume and also with the traffic and highway characteristics. The relation between critical headway and traffic volume for the highways under study is:

critical headway $=13.301-0.004 \mathrm{~V}, \quad \mathrm{R}=0.55$

In general, as the number of vehicles increases and percentage of trucks decreases, the percentage of vehicles with headway less than or equal to 3.2 seconds 
increases. However, the relation between vehicles with headway less than or equal to 3.2 seconds with a number of vehicles and percentage of trucks is shown in the following equation:

No. of vehs $\leq 3.2 \mathrm{sec}=-107.83+0.722 \mathrm{~V}, \mathrm{R}=0.96--$ (7) where,

No. of vehs : number of vehicles with headway $\leq 3.2$ second, and

$\mathrm{V}$ : total volume (veh/h).

The equation shows that the percentage of trucks was excluded from the relation.

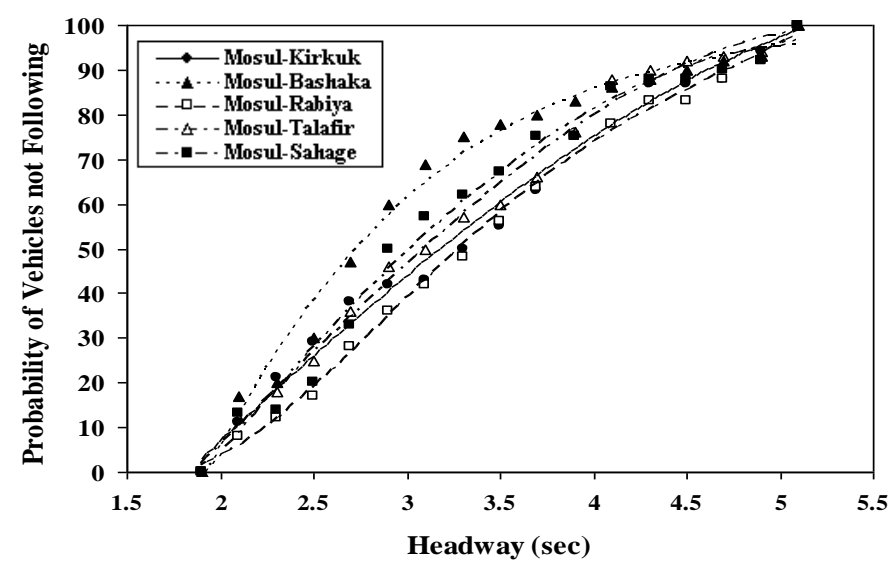

(a) Mosul Highways

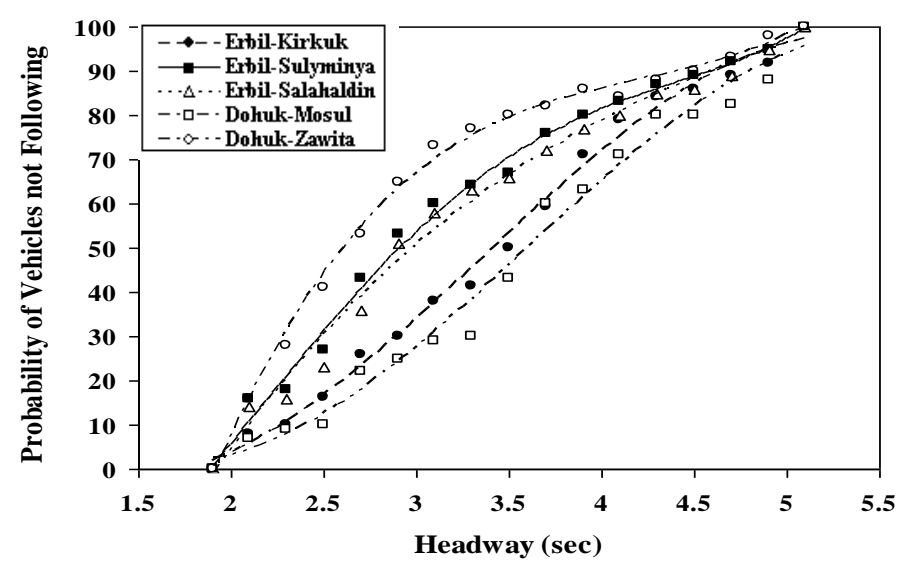

(b) Erbil and Dohuk Highways

Fig (3) : Probability of Vehicles not following at Different Headways

\subsection{Headway Modeling}

Numerous models have been reported in traffic engineering literatures to describe vehicle headway distribution. These models consist of composite models, which are a mixture of two distributions, representing headways of following (constrained) or non following (free) vehicles. In this study the vehicles are assumed to be constrained vehicles if both of the following conditions exist :

1. The headway between the vehicle and its preceding is equal to or less than $3.2 \mathrm{sec}$,
2. The time between the vehicle and the oncoming vehicle in the opposing direction is less than or equal to 15 seconds. Otherwise the vehicle is in free condition. In the highways under study, the best model for free vehicle is a shifted negative exponential distribution. While for constrained vehicles the best model is a lognormal distribution. The closeness of fit of free headway distribution to the observed values can demonstrated graphically by drawing a histogram of the observed and theoretical numbers of headways in each class. Figure (4) shows an observed and theoretical number of free vehicles for a Mosul-Rabiya highway as a sample. However, a statistical test of the closeness of fit of the theoretical distribution can be made by means of the chi - squared test. Results for this test show that there is no significant difference between the observed and theoretical headway distribution at the 5 percent level. For lognormal distribution of constrained vehicles, a quick test of fitting is by graphical means. The curve of a cumulative lognormal distribution on paper having a log scale on one axis and a normal probability scale on the other axis is a straight line. Figure (5) is a plot for Mosul-Basahaka highway. The proportion of constrained vehicles to the total volume of vehicles for all highways is shown in the following equation: Proportion of constrained vehicles $=0.0692+$ $0.0002 \mathrm{~V}, \mathrm{R}=0.65$--- (8) where, $\mathrm{V}$ : total volume (veh/h).

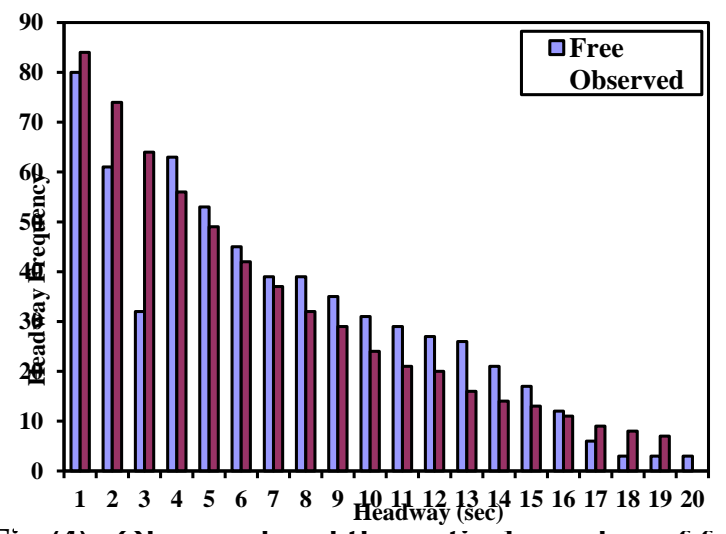

Fig (4) : Observed and theoretical number of free

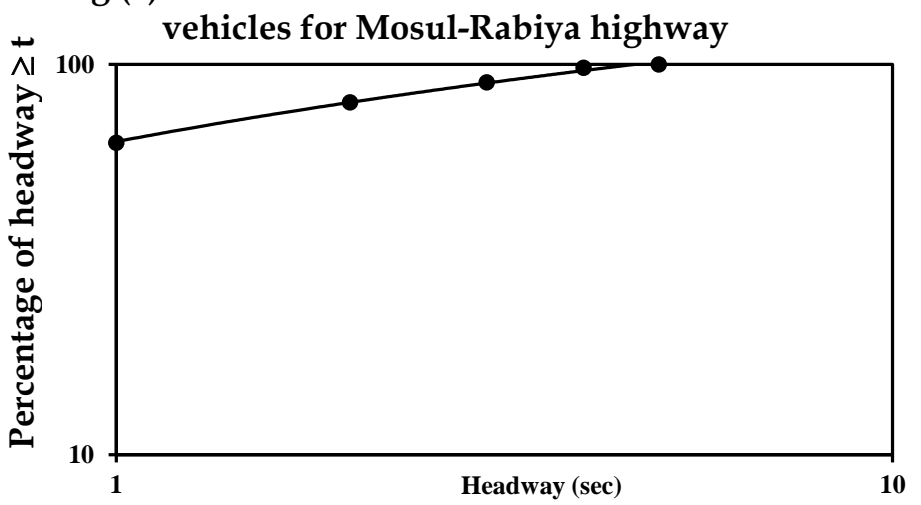

Fig (5) : Lognormal plots of constrained headway for Mosul-Bashaka Highway 


\section{CONCLUSION AND RECOMMENDATIONS}

Within the limitations of studied sites, the conclusions drawn from the analysis of the data are described below:

1. Critical headways are ranges between 2.5 to 4.0 seconds with a suitable critical headway of 3.2 second.

2 . The best headway model consists of composite model for free vehicles are a shifted negative exponential distribution. While for constrained vehicles are lognormal distribution. It is recommended to find the critical headway and modeling in mountains two-lane highways.

\section{REFERENCES}

1. Botma, H. (1988). Effects on traffic operation of a slow moving vehicle on two-lane rural roads. Paper Presented at 14th ARRB Conference, Canberra, Australia.

2. Buckley, D. J. (1962). Road traffic headway distributions. Australian Road Research Board Proceeding, Volume 1, Part 1.

3. Chandra, S., \& Kumar R. (2001). Headway modeling under mixed traffic on urban roads. Road and Transport Research.

4. Daou, A. (1966). On flow within platoons. Australian Road Research 2 (7).

5. Dawson, R. F. \& Chimini, L. A. (1968). The hyperlang probability distribution-A generalized traffic headway model. Transportation Research Record No. 230, Transportation Research Board, Washington, D. C.

6. Dommerholt, W., \& Botma, H. (1988). Model to determine operating quality on two-lane rural roads. Paper Presented at ITE 58th Annual Meeting, Vancouver, Canada.

7. Gerlough, D. L., \& Huber, M. J. (1975). Traffic flow theory - A Monograph. Transportation Research Board, Special Report 165, Transportation Research Board, Washington, D. C.

8. Grecco, W. L., \& Sword, E. C. (1968). Prediction of parameters for Schuhl's headway distribution. Traffic Engineering No. 38 (5).

9. Greenberg, I. (1966). The long-normal distribution of headways. Australian Road Research, 2 (7).

10. Guell, D. L., \& Virkler, M. R. (1988). Capacity analysis of two-lane highways. Transportation Research Record No. 1194, Transportation Research Board, Washington, D. C.

11. Highway Research Board. (1965).Highway Capacity Manual, Special report 87, Washington, D. C.

12. Highway Research Board. (1985). Highway Capacity Manual, Special report 209, Washington, D. C.

13. Highway Research Board. (2000). Highway Capacity Manual, Washington, D. C.

14. Hoban, C. J. (1980). Overtaking lanes on two-lane rural highway. Ph. D. Dissertation, Monash University, Glayton, Victoria, Australia.
15. Hoban, C. J. (1983). Towards a review of the concept of level of service for two-lane rural roads. Australian Road Research, Volume, 13, No. 3.

16. Hoban, C. J. (1984). Bunching on two-lane rural roads. ARRB Internal report AIR359- Australian Road Research Board, Nunawading.

17. Johnson, G. P. (1995). Highway capacity manual misses mark on rural highway capacity. Proceedings of the 65th Annual Meeting, Institute of Transportation Engineers.

18. Kell, J. H. (1962). Analyzing vehicular delay at intersections through simulation. Highway Research Board Bulltin No. 356.

19. Keller, H. (1976). Effect of a general speed limit on platoon of vehicles. Traffic Engineering and Control, No. 18.

20. Krumins, I. (1981). Capacity and level of service of two-lane rural highways in Alberta. Ph. D. Thesis, Department of Civil Engineering, University of Calgary. 21. Krumins, I.V. (1988). Modeling headway distribution on two-lane highways. Report to Alberta Research Council, Edmonton.

22. May, A. D. Jr. (1965). Gap availability studies. Transportation Research Record No. 72, Transportation Research Board, Washington, D. C.

23. McLean, J. R. (1989). Two-lane highway traffic operations - Theory and Practice. Gordon and Breach Science Publisher New York.

24. Ovuworie, G. C., Darzentas, J., \& McDowell, M. R. C. (1980). Free movers, followers and others: A reconsideration of headway distributions. Traffic Engineering and Control 28 (8/9).

25. Roy, R., \& Saha, P. (2018). Headway distribution models of two-lane roads under mixed traffic conditions: a case study from India. European Transport Research Review, 10:3.

26. Saha, P., Roy, R., Sarkar, K., \& Pal, M. (2017). Preferred time headway of drivers on two-lane highways with heterogeneous traffic. International letters, The International Journal of Transportation Research, Vol. 9.

27. Salter, R. J. (1990). Highways traffic analysis and design. Macmillan Publisher, Second Edition.

28. Schuhl, A. (1971). Probability theory applied to distribution of vehicles on two-lane highways. In Poisson and other distribution in the traffic, Eno Foundation for Transportation, Saugatuck.

29. Tolle, J. E. (1971). The lognormal headway distribution model. Traffic Engineering and Control, 13 (1).

30. Underwood, R. T. (1963). Traffic flow and bunching. Australian Road Research 8 (1). Australian Road Research Board. 
31. Van As, C. (2004). The development of an analysis method for the determination of level of service of twolane undivided highways in South Africa. Project Summary, South African National Roads Agency Limited.
32. Wolhuter, K. M. (1989). Headways on rural twolane roads. Roads and Transport Technology Report DPVT 56, CSIR, Pretoria. 